\title{
An empirical study on the effects of human resource supporting strategies on job satisfaction
}

\author{
Mohammad Khodaei Valahzaghard $^{\mathrm{a}^{*}}$, Fatemeh Afzali ${ }^{\mathrm{b}}$ and Saeeid Khodaei Valahzaghard ${ }^{\mathrm{c}}$
}

${ }^{a}$ Department of Accounting, Tehran North Branch, Islamic Azad University (IAU), Tehran, Iran

${ }^{b}$ Department of Management, Ghazvin Branch, Islamic Azad University (IAU), Qazvin, Iran

${ }^{c}$ Department of Management, Tehran North Branch, Islamic Azad University, Tehran, Iran

A R T I C L E I N F O AB S T A T

\section{Article history:}

Received March 22, 2012

Received in Revised form

May, 8, 2012

Accepted 11 May 2012

Available online

May 142012

Keywords:

Job satisfaction

Human resource management

LISREL

Banking industry

\begin{abstract}
One of the essential functions of human resource management is to take care of skilled employees. The process is normally divided into two categories: first category includes different activities such as having health and safety in working centers, performing healthy and sport programs and some other similar activities to save and improve employees' physical characteristics. The second group includes other important issues normally called benefit packages, which includes good health insurance and retiring plans. Whenever an organization provides good benefit package and supporting programs, there is a better job satisfaction among employee. In this paper, the effects of related services to support employee to reach job satisfaction and employee activities in one of Iranian banks called Mellat bank is investigated using 276 random samples. The results show that employees are relatively satisfied from the benefit package of the bank and they were relatively happy on working for such organization.
\end{abstract}

(c) 2012 Growing Science Ltd. All rights reserved.

\section{Introduction}

During the past few years, there have been significant advances in job satisfaction strategies since human resources play essential role on the success of organizations (Lengnick-Hall et al., 2009). In fact, employees are considered as the most valuable assets, where the success of a particular firm merely depends on. Human resources are the primary source of creating innovation through their creativities. An organization with no sense of innovation faces a tremendous risk since it can easily lose competition against the new rivals. Many organizations take advantage of outsourcing to do their duties and there is a need for skilled employees to handle different tasks, very easily (Shafiabadi, 2009). Therefore, it is important to find out the most important issues influencing job performance in organizations. 
Ma et al. (2003) emphasized on necessity of management policies, which would lead to meet what employees expect from the firm and explained that job satisfaction plays an important role for employee performance measurement. Steers and Porter (1991) explained that motivation of employees and workers depends on how they are treated in an organization and whenever employees are treated fairly, there is a better chance of reaching higher performance.

Marchant (1999) studied two factors of ability and motivation influencing job performance. Verom, in his study gained that there was a positive relationship between job satisfactions, job performance and performance level (Shafi Abadi, 2009). Ahmad and Schroeder (2003) investigated the effect of human resource management practices on operational performance by recognizing country and industry differences. They tried to generalize the efficacy of seven human resource management (HRM) practices in the context of country and industry, focusing primarily on the impacts of these practices on operations. Omidi (2008) studied the most important factors affecting job performance among experts of organization of physical education and the results obtained showed a significant positive relationship between motivation and job performance.

Providing an exciting and suitable environment with regard to material facilities and existence of material motivations and timely rewards by giving authority to use resources have led to progression and development of job function of organizational experts and organizational profit. The performance of banking industry highly depends on their employees since they are directly linked with banks' customers. While employee performance depends on number of different parameters, job satisfaction can be a function of salary and benefit package.

The skilled human force is defined as one of most useful tools of each organization to achieve its goals. There are literally a wide spectrum of factors according to level of people's needs influence on job performance. Therefore, it is possible that job performance of employees are affected by factors except the ones associated with organization. Consequently, this study seeks to model the employees' job performance in connection with motivational factors of organization in the field of maintenance strategies of human resources job satisfaction. Results of previous studies show that perception of each component can influence on several components. Most researchers believe that job performance is a multidimensional structure and two important aspects of these dimensions are underlying the task performance (Befort \& Hattrup, 2003) .

In this paper, we perform an empirical investigation on one of Iranian banks called Mellat, located in Iran. This paper is organized as follows.

\section{The proposed model}

The proposed study of this paper considers three hypotheses as follows,

1. Bank Mellat implemented effective methods to keep its employees and make them happy, which yields job satisfaction.

2. Bank Mellat has chosen appropriate strategy on its staff, which has positive effects on job function of the employees.

3. The job satisfaction of employees in bank Mellat has positive effect on employees function.

The present study, according to the applied applications and based on performance methods is survey which has examined relationships between variables and structural equation of modeling and the factors employees' job performance. The research environment is of information and tools for data collection are valid questionnaires that have required validity and reliability. 


\subsection{Statistical society, sample size and selection strategy}

The statistical research community consists of the banks' employees who work for Bank Mellat in Tehran city and the statistical sample includes 276 individuals from members of statistical community who were randomly selected in 2010 from different branches of Tehran city and the sampling was done using Kukran sample size estimation.

\subsection{Measuring instruments and methods of collecting and the research}

When we designed questionnaire of job satisfaction, the standard questionnaire was developed to measure job satisfaction based on five dimensions of payment, jobs, colleagues, opportunities of progression and for designing the questionnaire the size of system maintenance strategies of researcher who made questionnaire was used. Performance of staff and with the use of scores of two staff, the course of evaluation has been measured.

The variable of maintenance of human force with the use of 21 questions on the field of Health Medicine, Insurance and Retirement Services and Welfare were extracted. Variable of staff's performance was considered as the dependent variable. This variable with the use of 30 questions in the field of the variables of payment, job, opportunities of progression, the head quarter and coworkers were measured and extracted. We have used Likert scale to evaluate the relative importance of each factor.

The study has shown that the questionnaire besides having content validity, has validity of structure. The Cronbach Alpha was 0.894 and coefficient satisfaction questionnaire was 0.957, which are well above 0.70 and confirm the results and they are summarized in Table 1 . In order to investigate the internal structure of questionnaire the conformity factor analysis has been used. The results have shown that the coefficient factor markers with variables associated with it is significant and the tstatistic is bigger than 1.96. Thus, the validity of structures and the sizing tool has been approved. Table 2 to Table 4 show the validity results of the questionnaire.

\section{Table 1}

Results of the validity of questionnaires used in sizing of needed data

\begin{tabular}{llll}
\hline METHOD & Cronbach Alpha & Number of questions & Number of responses \\
\hline 1 & 0.894 & 21 & 276 \\
2 & 0.957 & 30 & 276 \\
\hline
\end{tabular}

\section{Table 2}

Results of Conformity factor analysis associated with validity of markers of questionnaires

\begin{tabular}{lllll}
\hline STRUCTURE'S & INDEX NAME & FACTOR LOAD & T-STATISTICS & RESULT \\
\hline KEEP AND & WELFARE SERVICES & 85.0 & 85.16 & POSITIVE AND SIGNIFICANT \\
MAINTAIN THE & HEALTH \& SAFETY & 84.0 & 47.16 & POSITIVE AND SIGNIFICANT \\
STAFFS & INSURANCE \& RETIREMENT & 50.0 & 37.8 & POSITIVE AND SIGNIFICANT \\
\hline \multirow{2}{*}{ JOB } & payment & 80.0 & 73.15 & POSITIVE AND SIGNIFICANT \\
SATISFACTION & job & 81.0 & 12.16 & POSITIVE AND SIGNIFICANT \\
& progression opportunities & 86.0 & 68.17 & POSITIVE AND SIGNIFICANT \\
& headquarter & 92.0 & 70.19 & POSITIVE AND SIGNIFICANT \\
\hline STAFF'S & COWorkers & 60.0 & 77.10 & POSITIVE AND SIGNIFICANT \\
FUNCTION & LAST EVALUATION & 96.0 & 13.20 & POSITIVE AND SIGNIFICANT \\
\hline
\end{tabular}


Table 3

Results of Conformity factor analysis

\begin{tabular}{|c|c|c|c|c|c|c|c|}
\hline \multicolumn{5}{|l|}{ measurement items } & \multicolumn{3}{|c|}{ Reliability and validity of the study measures } \\
\hline Construct & Item & Factor loading & t-value & $\mathrm{R}^{2}$ & CR & $\alpha$ & AVE \\
\hline \multirow{7}{*}{ Welfare services } & WS1 & 0.61 & 10.64 & 0.37 & \multirow{7}{*}{0.897509} & \multirow{7}{*}{0.866491} & \multirow{7}{*}{0.556209} \\
\hline & WS2 & 0.61 & 10.67 & 0.37 & & & \\
\hline & WS3 & 0.74 & 13.82 & 0.55 & & & \\
\hline & WS4 & 0.70 & 12.74 & 0.49 & & & \\
\hline & WS5 & 0.72 & 13.34 & 0.52 & & & \\
\hline & WS6 & 0.75 & 14.23 & 0.57 & & & \\
\hline & WS7 & 0.73 & 13.66 & 0.54 & & & \\
\hline \multirow{7}{*}{ Health and safety } & HS1 & 0.67 & 12.24 & 0.45 & \multirow{7}{*}{0.909551} & \multirow{7}{*}{0.883188} & \multirow{7}{*}{0.590688} \\
\hline & HS2 & 0.75 & 14.27 & 0.57 & & & \\
\hline & HS3 & 0.82 & 16.19 & 0.67 & & & \\
\hline & HS4 & 0.74 & 13.87 & 0.55 & & & \\
\hline & HS5 & 0.75 & 14.17 & 0.56 & & & \\
\hline & HS6 & 0.60 & 10.52 & 0.36 & & & \\
\hline & HS7 & 0.75 & 14.13 & 0.56 & & & \\
\hline \multirow{7}{*}{$\begin{array}{l}\text { Insurance } \\
\text { retirement }\end{array}$} & IR1 & 0.72 & 13.35 & 0.52 & \multirow{7}{*}{0.921946} & \multirow{7}{*}{0.900438} & \multirow{7}{*}{0.628311} \\
\hline & IR2 & 0.68 & 12.33 & 0.46 & & & \\
\hline & IR3 & 0.78 & 14.86 & 0.60 & & & \\
\hline & IR4 & 0.72 & 13.24 & 0.51 & & & \\
\hline & IR5 & 0.82 & 16.02 & 0.67 & & & \\
\hline & IR6 & 0.77 & 14.76 & 0.60 & & & \\
\hline & IR7 & 0.72 & 13.45 & 0.52 & & & \\
\hline
\end{tabular}

\section{Table 4}

Results of Conformity factor analysis

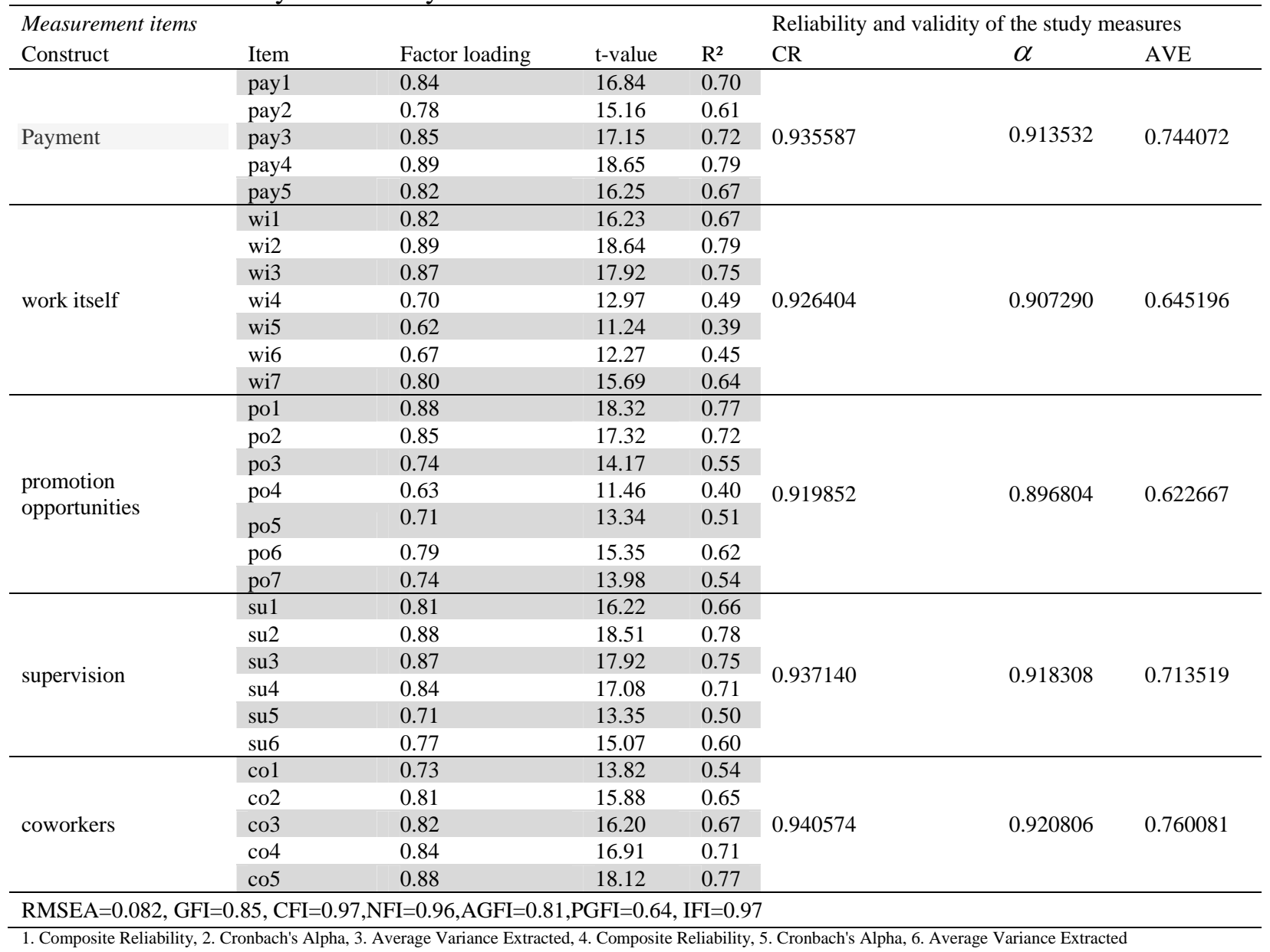




\section{Analysis of the data of the research}

Values of each variable with the use of related responses have been calculated and with the use of statistical software packages and with respect to two series of statistics, mean descriptive statistics and inferential statistic have been analyzed. In order to calculate the indices tended to the center and distribution the descriptive statistics for testing these hypotheses is used.

\subsection{Descriptive Analysis of Data}

Description of collected data includes two parts of describing personal profile and population cognition of sample group and the research variables. About descriptive indicators, these features with respect to their scales, suitable indices have been applied. Frequency and percentage of frequency and characteristic fashion of individual members of statistical sample are given in Table 5 .

\section{Table 5}

Frequency and percent of frequency of top employees

\begin{tabular}{|c|c|c|c|c|c|}
\hline characteristic & SUBGROUP & MODE & $\%$ & NO & MODE \\
\hline \multirow[b]{2}{*}{ SEX } & Female & \multirow[b]{2}{*}{ MALE } & 42.0 & 116 & \multirow{2}{*}{ MALE } \\
\hline & Male & & 58.0 & 160 & \\
\hline \multirow{5}{*}{ EDUCATION } & Under diploma & & 1.1 & 3 & \multirow{5}{*}{ BACHELOR } \\
\hline & Diploma & & 24.6 & 68 & \\
\hline & Associate degree & BACHELOR & 8.0 & 22 & \\
\hline & Bachelor & & 57.2 & 158 & \\
\hline & M.A and upper & & 9.1 & 25 & \\
\hline \multirow{5}{*}{ Work experience } & Between 1-5 years & & 12.7 & 35 & \multirow{5}{*}{ Between 6-10 years } \\
\hline & Between 6-10 years & & 37.7 & 104 & \\
\hline & Between 11-15 years & Between 6-10 years & 15.9 & 44 & \\
\hline & Between $16-20$ years & & 25.7 & 71 & \\
\hline & More than 20 years & & 8.0 & 22 & \\
\hline \multirow{4}{*}{ ORGANIZATIONAL POST } & Employee & & 50.0 & 138 & \multirow{4}{*}{ Employee } \\
\hline & The head of department & Fmploveo & 18.5 & 51 & \\
\hline & The assistant of department & Біпрioyee & 27.9 & 77 & \\
\hline & Manager & & 3.6 & 10 & \\
\hline MARITAL STATUS & Unmarried & Married & 19.2 & 53 & Married \\
\hline
\end{tabular}

To describe the statistical indicators, the indicators with trends of central dispersion are used and the results are given in Table 6 . The results show that the mean of strategy variables of human preservation and job satisfaction are higher than the average of theoretical measured scale. The coefficients of Chulgy variables of maintenance system and personnel performance are negative and job satisfaction is positive. Low values of coefficients of variables of Chulgy and job satisfaction of 96.1 is symmetrical. Strain coefficients of maintenance system variables and job satisfaction are negative and variable of staff performance is positive.

Table 6

Indexes with central tendency and distribution of variables of case study

\begin{tabular}{|c|c|c|c|c|c|c|}
\hline \multirow[b]{2}{*}{ VARIABLE } & \multirow[b]{2}{*}{ MEAN } & \multirow{2}{*}{$\begin{array}{l}\text { DEVIATION } \\
\text { STANDARD }\end{array}$} & \multirow[b]{2}{*}{ VARIANCE } & \multicolumn{3}{|c|}{ DEVIATION } \\
\hline & & & & \multicolumn{3}{|c|}{ CHULGY } \\
\hline MAINTENANCE SYSTE & M3.411 & 0.599 & 0.358 & -0.249 & $-0.391-1.695$ & -1.338 \\
\hline JOB SATISFACTION & 3.367 & 0.771 & 0.594 & 0.250 & -0.4481 .706 & -1.531 \\
\hline EMPLOYEES’ FUNCTIC & N29.497 & 0.973 & 0.946 & -2.326 & $5.372-15.859$ & 18.379 \\
\hline
\end{tabular}

\subsection{Inferential Analysis of Data}

The conceptual model of research with the use of model seeking structural equation has been examined. Modeling of structural equation is a multivariate analysis technique from family of 
multiple regression and general linear model that allows set of regression equations are examined as well. Finding a comprehensive structural equation model is a statistical approach to test the hypothesis between the observation and latent variables (Byrne, 1998). Results obtained from conceptual model of Statistical Society case study are given in Tables 7, Table 8 and Fig. 1. The conceptual model with the use of maximum of exponential is examined and the parameters of model are evaluated via given data. The root mean square error indices with 0.075 and Normal Fit Index of 0.98, Normal Fit Index of 0.98, the Goodness of Fit Index with the 0.95 and Root Mean Square Residual of 0.043 have suuported from being appropriate of model and coordination of the statistical sample with conceptual model.

\section{Table 7}

Indexes of relationships between case study variables in structural model of the research (Total effect: 0.64, Indirect effect :0.31, direct effect:0.33, RMSEA=0.070, GFI=0.95, CFI=0.99,NFI=0.98,AGFI=0.91,PGFI=0.54, IFI=0.99)

\begin{tabular}{llllll}
\hline independent variable & Dependent variable & INDEX & coefficient & standard error & $\mathrm{R}^{2}$ \\
\hline MAINTENANCE & JOB SATISFACTION & GAMMA & .87 & 0.045 & 0.76 \\
MAINTENANCE & EMPLOYEES’ FUNCTION GAMMA & .33 & 0.047 & 0.44 \\
JOB SATISFACTION & EMPLOYEES’ FUNCTION & BETA & .35 & 0.063 & \\
\hline
\end{tabular}

Table 8

Measurement items (RMSEA=0.082, GFI=0.85, CFI=0.97,NFI=0.96,AGFI=0.81,PGFI=0.64, IFI=0.97)

\begin{tabular}{lllll}
\hline Construct & Item & Factor loading & t-value & $\mathrm{R}^{2}$ \\
\hline \multirow{3}{*}{ MAINTAIN } & Welfare services & .88 & $*$ & 0.77 \\
& Health and safety & .89 & 19.33 & 0.80 \\
& Insurance and retirement & .57 & 10.08 & 0.32 \\
\hline \multirow{3}{*}{ JOB SATISFACTION } & .82 & $*$ & 0.67 \\
& Payment & .84 & 16.61 & 0.70 \\
& work itself & .84 & 16.68 & 0.71 \\
\cline { 2 - 5 } & promotion opportunities & .92 & 19.11 & 0.85 \\
& supervision & .60 & 9.11 & 0.36 \\
\cline { 2 - 5 } performance & coworkers & .95 & $*$ & 0.91 \\
& Evaluation score & .91 & 19.09 & 0.82 \\
\hline
\end{tabular}

*Parameter set equal to 1.0 for identification model

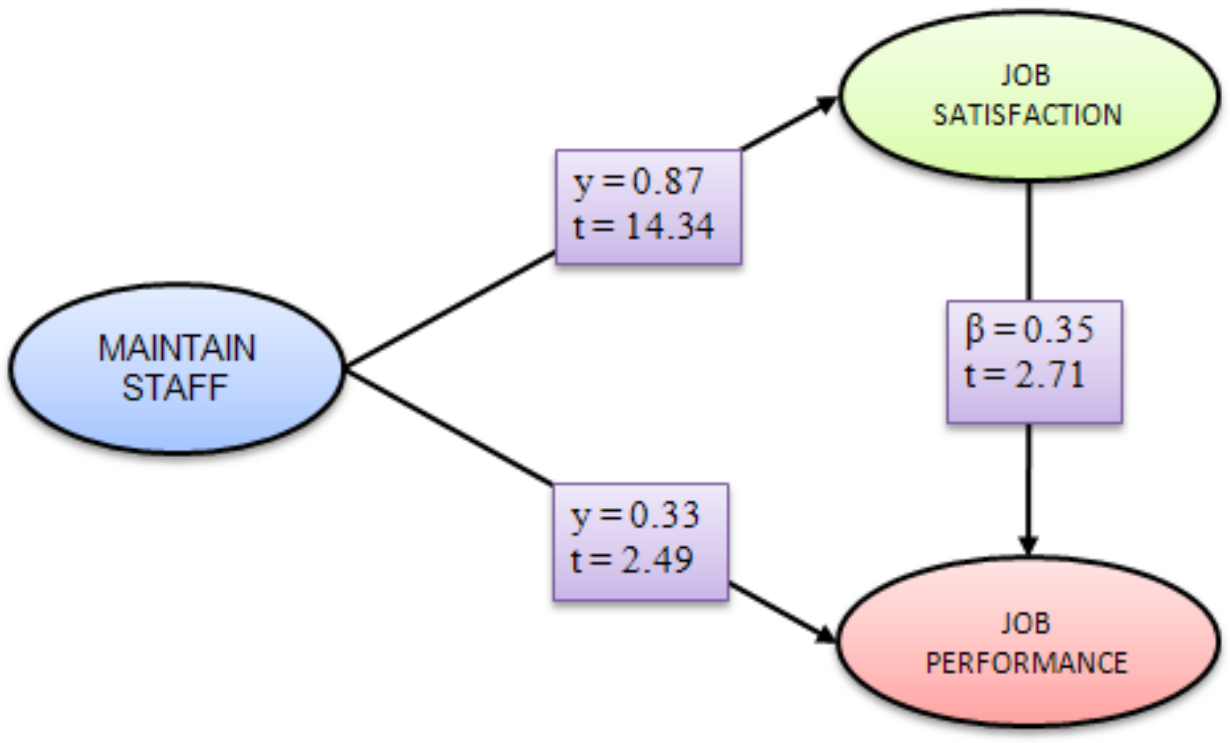

Fig. 1.The diagram of the evaluated standard coefficients between Maknoon Variables 
Table 8

Indexes of relationships between Maknoon independent variables with dependent indexes

\begin{tabular}{llllll}
\hline EFFECTIVE & AFFECTED VARIABLE & COEFFICIENT & \multicolumn{2}{l}{ Evaluated } & $\mathrm{t}$ \\
\cline { 2 - 6 } VARIABLE & & NOT & STANDARDIZED & & \\
\hline MAINTENANCE & PAYMENT & 1.03 & 0.68 & 0.07 & 29.15 \\
MAINTENANCE & JOB & 0.94 & 0.66 & 0.07 & 99.13 \\
MAINTENANCE & OPPORTUNITY & 1.00 & 0.61 & 0.07 & 64.13 \\
MAINTENANCE & HEADQUARTER & 1.28 & 0.84 & 0.08 & 73.16 \\
MAINTENANCE & COLLEAGUES & 0.82 & 1.05 & 0.08 & 10.05 \\
MAINTENANCE & LAST FUNCTION & 1.60 & 1.06 & 0.16 & 10.08 \\
MAINTENANCE & FUNCTION OF BEFORE & 1.62 & 0.58 & 0.16 & 9.89 \\
JOB & LAST FUNCTION & 0.84 & 0.63 & 0.36 & 2.34 \\
JOB & FUNCTION OF BEFORE & 0.85 & 0.64 & 0.36 & 2.34
\end{tabular}

\section{Results and Findings}

In this section, we preset detiles of the results of our survey based on the implementation of structural equation.

4.1 The first hypothesis: Bank Mellat implemented effective methods to keep its employees and make them happy, which yields job satisfaction. As we can observe, the calculated t-student is 29.15, which is well above the desired level of 1.96 when the level of significance is five percent. Therefore, we can reject the null hypothesis and conclude that the proposed bank has chosen proper strategy to keep its staff. The other statistical observation is for Gamma, which is calculated as 0.90 indicating the impacts of different variable on job satisfaction. The coefficient of 0.807 also explains variance of strategies explained for this strategy. Therefore, it can be concluded that bank Mellat has chosen appropriate strategy to take care of its staff, which yields job satisfaction of the employees.

4.2 The second hypothesis: Bank Mellat has chosen appropriate strategy on its staff, which has positive effects on job function of the employees.

According to the results, the t-student is 1.747 and it is smaller than 1.96, thus, the zero hypothesis in level of $95 \%$ of assurance is rejected and considering that the coefficient is positive and the statistics is positive, so, the hypothesis of research is accepted as healthy hypothesis. The statistics of Gamma is 0.28 , which indicates the amount of the various coefficient of human force retention in bank Mellat connection to Job satisfaction. Note that the coefficient of 0.374 indicates explainable variance of strategies variables on human resources of the bank. Therefore, it can be accepted that human force retention in bank Mellat has positive effect (90\%) on job satisfaction of the employees, but at 95\% this is not meaningful.

4.3 The third hypothesis: The job satisfaction of employees in bank Mellat has positive effect on employees function.

The t-student calculated with the amount of 2.25 is larger than 1.96, thus, the zero hypothesis in level of $99 \%$ of assurance is rejected and considering that the coefficient is positive and the statistics is positive we can conclude that the hypothesis of research is accepted as healthy hypothesis. The statistics of Beta with 0.37 indicates the amount of the various coefficient of human force retention in bank Mellat is connected with Job satisfaction. The coefficient of 0.807 indicates explainable variance of strategies variables explained preservation and maintenance human force in bank Mellat. Therefore, it can be accepted that bank Mellat has chosen appropriate strategy to take care of its staff and the strategies have positive effects on job satisfaction of the employees. 


\section{Conclusion}

In this paper, we have presented an empirical study to measure the impact of supporting strategies in taking care of employees. We have discussed that when the strategies come with supportive programs there will be a better job satisfaction among employees. The proposed study of this paper considered three hypotheses. The first one investigated whether Bank Mellat implemented effective methods to keep its employees and make them happy, which yields job satisfaction. The second hypothesis stated that Bank Mellat had chosen appropriate strategy on its staff, which has positive effects on job function of the employees. Finally, the last hypothesis stated that the job satisfaction of employees in bank Mellat had positive effect on employees function. The results of our analysis confirmed all hypotheses, which means the proposed bank were in good condition of taking care of its employees.

\section{Acknowledgment}

The authors would like to thank the officials of bank Mellat for their supports in accomplishing this survey.

\section{References}

Ahmad, S., \& Schroeder, R.G. (2003). The impact of human resource management practices on operational performance: recognizing country and industry differences. Journal of Operations Management, 21(1), 19-43

Befort, N., \& Hattrup, K. (2003). Valuing tax and contextual performance: Experience, job roles and rating of the importance of job behaviors. Applied H. R.M. Research, 8(1), 17-35.

Byrne, B. M. (1998). Structural Equation Modeling With Lisrel, Prelis, and Simplis: Basic Concepts, Applications, and Programming (Multivariate Applications Series). $1^{\text {st }}$ ed., Psychology Press.

Lengnick-Hall, M.L., Lengnick-Hall, C.A., Andrade, L.S., \& Drake, B. (2009). Strategic human resource management: The evolution of the field. Human Resource Management Review, 19(2), 64-85

Ma, C.C., Samvels, M.E., \& Alexander, J. W. (2003). Factors in nursing job satisfaction. Journal of Nursing Adminstration, 33 (5), 293-299.

Marchant, T. (1999). Strategies for improving individual performance and job satisfaction at Meadowvale Health. Journal Of Management Practice, 2(3), 63-70, (In Farsi).

Omidi, A., \& Sajadi, S. (2008). Factors of Affecting Job Performance Experts Physical Education Organization. Tehran, Tarbiat Moaalem University (In Farsi).

Steers, RM., \& Porter, LW. (1991). Motivation and Work Behavior. New York, McGraw Hill. 